\title{
An E-Conversation with Prof. Neal Chung
}

\author{
Subhas K. Sikdar
}

Published online: 13 September 2014

(C) Springer-Verlag Berlin Heidelberg (Outside the USA) 2014

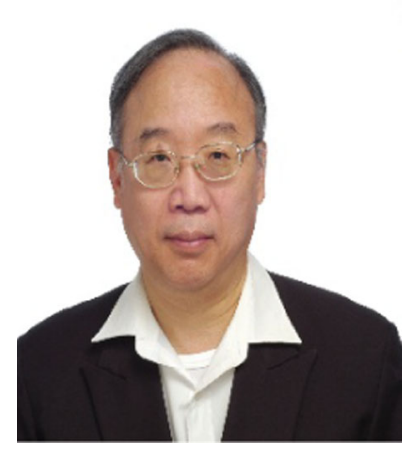

Prof. Chung

Prof. Chung is a Provost's Chair and Professor in ChBE Department, NUS. He had worked for Hoechst Celanese for 13 years in USA and then joined NUS in 1995. He has 550 journal papers. He was a Senior Consultant for Hyflux, led and built its membrane research in 2004-2008. He is an Editor of Journal of Chemical Engineering Research and Design (CHERD) and editorial board members of 20 journals including Journal of Membrane Science, AIChE Journal, I\&EC Research. He became a Fellow in the Academy of Engineering Singapore in 2012.

Subhas Sikdar: Neal, In recent times you have established a large research focus on pressure reduced osmosis (PRO) and forward osmosis (FO) for producing clean water. You have an enviable funding and research success in this line of technology development. At this juncture,

S. K. Sikdar $(\square)$

Cincinnati, OH, USA

e-mail: sikdar.subhas@epa.gov what other applications do you think PRO and FO can achieve?

Prof. Neal Chung: There are two immediate applications for the FO technology. One is for the oil-water separation, the other is for heavy metals removal.

\section{Oil-water separation}

Oil-water separation has received worldwide attention recently due to large amounts of discharged oily wastewater from hydraulic fracturing and other industries. In oily wastewater, oil exists in several forms such as free oil (i.e., oil droplets, larger than $150 \mu \mathrm{m}$ diameter), dispersed oil (i.e., oil droplets between 20 and $150 \mu \mathrm{m}$ diameter), and emulsified oil (i.e., oil droplet less than $20 \mu \mathrm{m}$ in diameter).

Free oily wastewater and dispersed oily wastewater can be treated by many methods such as gravity and skimming, dissolved air flotation, de-emulsification, coagulation, and flocculation techniques. However, there is no effective method to treat stable emulsified oily wastewater. Recently, promising results have been demonstrated by using single- and double-skinned FO membranes.

For example, one can employ forward osmosis (FO) processes to treat the stable oil-water emulsions containing oil concentration up to $200,000 \mathrm{ppm}$. By means of single-skinned FO membranes, water can be recovered at a relatively high flux using $1 \mathrm{M} \mathrm{NaCl}$ as the draw solution. Moreover, this FO membrane can achieve an oil rejection of $99.88 \%$ to produce water with a negligible oil level. However, membrane fouling by oil was noticed. Therefore, a novel double-skinned FO 
membrane with a high water flux was developed to minimize fouling.

The double-skinned FO membrane comprises a fully porous sublayer sandwiched between a truly dense skin for salt rejection and a fairly loose skin for emulsified oil particle rejection. In other words, the dense skin is a polyamide synthesized via interfacial polymerization while the loose skin is made from a self-assembled sulfonated pentablock copolymer (Nexar ${ }^{\mathrm{TM}}$ copolymer). The doubleskinned membrane exhibits a higher water flux and a lower reverse salt transport than the single-skinned one. The double-skinned membrane also has a much lower fouling propensity than the single-skinned one.

Wastewater from hydraulic fracturing contains surfactants, and chemicals such as formic acid or acetic acid as biocide or for acid treatment. A hybrid forward osmosismembrane distillation (FO-MD) system was also developed to treat the oily wastewater containing petroleum, surfactant, $\mathrm{NaCl}$, and acetic acid. Oily wastewater with a relatively high-salinity level could be effectively treated by the FO-MD hybrid system to recover water while maintaining a large water flux. At least $90 \%$ feed water recovery could be readily attained with only trace amounts of oil and salts, and the draw solution was re-generated for the next rounds of FO-MD operations. Interestingly, a significant amount of acetic acid was also retained in the permeate for further reuse as a chemical additive during the hydraulic fracturing.

\section{Heavy metal removal}

Currently, heavy metal contamination has become a severe environmental issue because of the exponential increase in the use of heavy metal compounds in various industrial processes. Since heavy metals cannot be metabolized by the body or decomposed naturally, they tend to accumulate inside the body and cause severe body dysfunction. Hence, removal of toxic heavy metal ions has become a top priority for many countries in wastewater treatment.

Several techniques have been proposed such as chemical precipitation, flotation, ion exchange, electrochemical deposition, adsorption, and membrane filtration. However, each aforementioned technique suffers from certain drawbacks. For example, the cost of chemical precipitation and flotation is usually high, while the disposal of extra sludge generated from these processes incurs extra cost. Ion exchange cannot handle concentrated metal solutions due to fouling by organics and other solids in the wastewater. Moreover, ion exchange is non-selective and is highly sensitive to the $\mathrm{pH}$ of the solution. Adsorption has the advantages of low-cost and rapid adsorption but it suffers from poor selectivity and slow regeneration.
Membrane technology has been proven as a feasible option in wastewater treatment due to its high rejection to contaminants, such as organic compounds or dye molecules, and low fabrication cost. Nanofiltration (NF) is an effective method for wastewater treatment and heavy metal removal by means of size exclusion and Donnan exclusion. However, NF membranes suffer from high fouling tendency, which result in reduced productivity and extra operational cost. Besides, insufficient rejection of heavy metal ions by NF processes in water treatment leads to extra cost on further purification.

A novel forward osmosis (FO) process has been demonstrated for the first time to remove heavy metal ions from wastewater. The proposed FO process consists of a thin-film composite (TFC) FO membrane made from interfacial polymerization on a macrovoid-free polyimide support and a novel bulky hydroacid complex as the draw solute to minimize the reverse solute flux. Six 2,000 ppm heavy metal solutions were tested and successfully demonstrated. They are $\mathrm{Na}_{2} \mathrm{Cr}_{2} \mathrm{O}_{7}, \mathrm{Na}_{2} \mathrm{HAsO}_{4}, \mathrm{~Pb}\left(\mathrm{NO}_{3}\right)_{2}$, $\mathrm{CdCl}_{2}, \mathrm{CuSO}_{4}, \mathrm{Hg}\left(\mathrm{NO}_{3}\right)_{2}$. Water fluxes around $11 \mathrm{~L} / \mathrm{m}^{2} / \mathrm{h}$ $(\mathrm{LMH})$ were harvested with heavy metals rejections of more than $99.5 \%$. This FO performance outperforms most NF processes. In addition, the high rejections were maintained at $99.5 \%$ when a more concentrated draw solution $(1.5 \mathrm{M})$ or feed solution $(5,000 \mathrm{ppm})$ was utilized. Furthermore, rejections greater than $99.7 \%$ were still achieved with an enhanced water flux of 16.5 LMH by operating the FO process at $60{ }^{\circ} \mathrm{C}$. These impressive heavy metal rejections and satisfactory water flux under various conditions may open up new perspectives of using FO systems for the treatment of heavy metals-laden wastewater.

SKS I will come back to FO again a little later, but before that, considering that PRO is largely unknown outside of the membrane aficionados, please give us a summary of how PRO works, what is its relationship, if any, to FO and what potential applications look attractive for PRO.

NC The concept of osmotic energy generation was proposed about 60 years ago, but most of the early works were discontinued due to the lack of effective membranes, which are the hearts of osmotic power systems. Statkraft of Norway is the first company that pioneered serious research on osmotic power and built the first prototype plant in 2009 by mixing river water and seawater across a semi-permeable membrane.

Theoretically, the river water will automatically transport across the semi-permeable membranes to dilute the seawater because of the chemical potential difference across the membrane. If the seawater compartment is 
fixed, then the pressure in the seawater compartment will increase and drive a hydro-turbine for power generation. At steady state operations, the operating pressure is about 13.5 bar which is equivalent to a water column of about $135 \mathrm{~m}$ in a hydropower plant. The estimated global osmotic energy that can be harvested from mixing ocean and river waters is in the order of about 1,750-2,000 TWh per year, which is more than $10 \%$ of the world energy consumption.

Since membranes for both FO and pressure retarded osmosis (PRO) processes are semi-permeable membranes, we originally thought that conventional FO membranes can be used for PRO processes. The results were very disappointing. This was due to the fact that most conventional FO membranes were designed for no- or lowpressure environments, as a result currently available FO membranes are likely to be damaged under PRO operations.

During my visit to Statkraft in 2011, I noticed that the PRO membranes used in Statkraft were only operated at about 6 bar because of membrane limitations. Thus, membrane design for power generation under highsalinity gradients will be significantly different from FO membranes used in conventional low-pressure environments.

If $\mathrm{RO}$ retentate is to be used as the draw solution, then the salinity gradient between RO retentate and river water is much greater than that between seawater and river water (about 7.9-8.5 vs. $3.5 \mathrm{wt} \%$ ). The former can result in a much higher osmotic pressure and osmotic energy than the latter, but they also create tremendous challenges for membrane scientists to design high flux membranes with super high mechanical strengths. However, if osmotic power generation and RO plants can be successfully integrated, not only can it make seawater desalination less energy dependent and more sustainable but also significantly alleviate the disposal and environmental issues of waste $\mathrm{RO}$ retentate. In addition, since the RO retentate has been well pre-treated in its previous processes, it can significantly reduce the membrane fouling in the high-pressure compartment. As a result, the integration may save some of expensive pre-treatment costs originally required for seawater before PRO.

So far several high-performance PRO membranes have been developed by NUS. For example, flat asymmetric PRO membranes have been developed with osmotic power density up to $18 \mathrm{~W} / \mathrm{m}^{2}$ that can withstand a pressure up to 22 bar using $1 \mathrm{M} \mathrm{NaCl}$ and DI water as feeds. Similarly, PRO hollow fibers with osmotic power density up to $25 \mathrm{~W} /$ $\mathrm{m}^{2}$ that can withstand a pressure up to 20 bar have also been developed.
SKS Statkraft had announced the design and construction of a 2 MW PRO power generating pilot plant in Norway, and it seems now that the project has been abandoned. We therefore have to wait to see the future of PRO. But as you said, FO in your example appears to work well for heavy metals removal from wastewaters. Perhaps there are other niche applications of FO one could think of. From the state of the art now in FO research, (1) briefly, what are the key advancements that we need to make FO cost-effective and competitive with other separation processes, such as adsorption-desorption, and other membrane approaches?, and (2) what do we know about the nature of membrane fouling in FO? Is the challenge essentially the same as in other membrane operations? Or, would it require different innovations?

NC The recent announcement of Statkraft withdrawing from the PRO pilot study was not surprising to me. According to my previous visit, the engineers from Statkraft told us that extensive pre-treatment processes must be conducted to remove foulants from both river and seawater feeds before entering the PRO pilot. In addition, two long pipes of about 100 and $300 \mathrm{~m}$ were employed to convey both feeds to the pilot. An additional high pressure pump was needed to pressurize the seawater. Since the salinity gradient between seawater and river water is low, there is not much economic and energy gain when you compare the energy generated from the PRO plant and the energy consumed in pretreatment, pumping the feeds and pressurizing the seawater compartment.

Therefore, I believe that future PRO studies will mainly focus on the use of RO retentate and NEWater retentate (i.e., waste of recycled water). In addition to creating much greater osmotic energy, the new approach can save expensive pre-treatment costs because both retentates have been well pre-treated in their previous processes, which can also significantly reduce the membrane fouling. Furthermore, since the RO retentate is already under pressure, there is no need to have an additional pump to pressurize the high pressure compartment as in the case of mixing seawater and river water for PRO.

In terms of fouling, extensive studies have proven that FO membranes have more reversible fouling than RO membranes because the former does not involve high pressures. On the other hand, fouling on PRO membranes may be quite different. It may be a new area for scientific studies. In addition, fouling on flat sheet and hollow fiber membranes under PRO processes may be quite different because the negative interactions between the spacer and 
flat sheet membranes. Flat sheet membranes may be deformed by the spacer under the PRO process.

Since FO membranes show much less fouling tendency, an integration of FO and RO plants has been proposed by many people. For example, one can lower seawater concentration before entering RO plants by using seawater as a draw solute to draw clean water across FO membranes from wastewater. As a result, the seawater concentration is diluted and the energy consumption for SWRO becomes lower. In addition, one can dilute RO retentate by using it as a draw solute to draw water across FO membranes from wastewater so that the diluted RO retentate can be disposed of.

SKS Early in the conversation you made the technological cases for FO in oil-water separation and heavy metals removal. Indeed the laboratory results do look promising. Are you aware of strong industry interest in exploiting these technologies at present or is it still early in the development of such business opportunities?

NC According to Wikipedia (http://en.wikipedia.org/ wiki/Hydraulic_fracturing), hydraulic fracturing is one of the key technologies to extract unconventional oil and gas resources. Many refineries have used it to gain extra access to relatively inexpensive shale oil. The National Petroleum Council estimates that hydraulic fracturing will eventually occupy nearly $70 \%$ of natural gas development in North America. Thus, many companies are aiming at using FO technologies for the water recycle in this application. Several companies have approached and consulted with me, some of them have worked with me. At this moment, it is hard for me to release the company names. For heavy metals removal, since draw solutes design and regeneration is involved, I suspect, commercialization will take more time.

SKS You live in Singapore which has become a significant hub of research on water, especially drinking water. Some of the multi-national water technology companies have their R\&D presence there. You also have two prominent universities both of which have strong water research capabilities. Singapore also hold the Water Week every other year where several thousand people from all over the world converge to exchange ideas and see demonstrations on water technologies. Briefly, beyond technology development, what else in water research Singapore is doing or must do to keep the momentum and secure its leadership role?
NC The success of Singapore's water R\&D is largely due to its commitment and investment in R\&D to ensure sustainability in water. Water has been identified as a key growth sector in Singapore, and the Environment and Water Industry Programme Office (EWI), led by Singapore's national water agency PUB and other partner agencies, spearheads this growth through advancing R\&D in the field and positioning Singapore as a global R\&D base for environment and water solutions. Funding opportunities for both basic and applied R\&D projects, as well as programmes for expediting commercialisation of their results are abundant.

Beyond funding, Singapore also provides a global testbed for new ideas and technologies. International water companies recognize Singapore for its ready access to testing their products in PUB's water facilities and infrastructure, and for the synergy in constructive collaboration with PUB and local research institutes. These R\&D projects range from laboratory-scale systems to demonstration plants. In fact, Singapore seeks to foster the growth of these innovations by facilitating the testing of products, processes, systems and services. By establishing proven track records, new technologies can become competitive in the water market. PUB has many facilities-including its waterworks, water reclamation plants, NEWater plants, and reservoirs - that can be made available as industrial testbeds for both public- and private-sector innovators.

Today, Singapore is recognized as a global hydrohub with 130 water companies and 28 research centres in a vibrant water industry ecosystem. Many countries see Singapore as a successful model for water management, where technologies and solutions developed and used here can be applied to tackle their countries' water challenges. Many companies have also set up headquarters and research centres in Singapore to target opportunities beyond the shores of Singapore.

The world is rapidly changing, and there are many new challenges to ensuring water sustainability, such as climate change, rising energy costs, competing land use. In particular, the global industrial water sector ranks second in water consumption, consuming an estimated $25 \%$ of global water demand, and industries are searching for innovative solutions to improve water sustainability across the value chain. The links that these companies build through their research collaborations and test-bedding, as well as projects with PUB and the industrial sector in Singapore, give them a competitive advantage when they bid for overseas projects. Singapore will continue to work with the industry on developing innovative water solutions, not only for PUB's needs, but for the industrial water sector world-wide. 
SKS Neal, you enjoy global reputation as a premier membrane researcher. At your University you direct the research of a large group of graduate and postgraduate researchers learning advanced skills, working in well-equipped facilities. You also lead a very simple life, working most of your waking hours. Our readers would be curious to know what do owe you your considerable success to?

NC There are many contributing factors. First and foremost, it is by God's grace that I can achieve this honor and together with Singapore, KAUST and my family supports. I am a very average person. Without God's blessings, Singapore, KAUST and my wife's strong supports, I cannot accomplish much. As a Christian, I have learnt from the Bible to live a simple life in the last 13 years. Thus, I have time to think of research, write proposals and find solutions to overcome the challenges. In addition, God has given me many intelligent students and staff. As a result, we can inspire one another, work together to overcome challenges and excel our research productivity.
SKS Neal, I thank you for taking the time to have this E-conversation with me. I hope there is much to learn here from your success and from your experience in working in membrane research. 